\title{
Stormy weather ahead
}

\author{
AMANDA LEIGH HAAG
}

\begin{abstract}
Stormy debates continue between scientists over the evidence linking hurricanes to global warming as the Atlantic hurricane season gets underway.
\end{abstract}

It remains to be seen whether the Atlantic hurricane season, which officially started on 1 June, will be as fierce as forecasts are predicting, but it's safe to say that the stormy debates over the link between hurricanes and global warming will continue well into the future. Scientists with the National Oceanic and Atmospheric Administration (NOAA) are predicting an above-normal hurricane season for the Atlantic, with 13 to 17 named storms and the possibility of three to five major hurricanes. Tropical or named storms are less extreme events than hurricanes; tropical cyclones qualify as hurricanes when they reach wind speeds greater than $74 \mathrm{~m} . \mathrm{p}$.h. Over the last two years, a spate of research findings - the first ${ }^{1}$ of which was published, uncannily, just prior to Hurricane Katrina - have left parts of the scientific community sharply divided over whether tropical storms are becoming more powerful and more frequent, and if so, to what degree warming ocean temperatures linked to climate change are to blame. A handful of recent studies are adding even more complexity to the debate.

\section{COUNTING CYCLONES}

In May, Christopher Landsea, a scientist with the National Hurricane Center in Miami, reported in $\operatorname{Eos}^{2}$ that the apparent trend in increasing frequency of tropical cyclones is mostly, if not entirely, an artifact of undercounts in the early 1900s, rather than a quantifiable change in the number of hurricanes. Landsea disagrees with reports that sea surface temperatures are having a measurable effect on tropical cyclone activity, including a study that found a doubling of tropical cyclones over the last 100 years linked to global warming ${ }^{3}$.

In the first half of the twentieth century, hurricanes over the open seas were recorded only in the sparse regions of the ocean where ships crossed, and wind-speed measurements were confined to the portion of the storms that shipping vessels happened to encounter. According to Landsea, this led to under-reporting in both hurricane frequency and intensity.

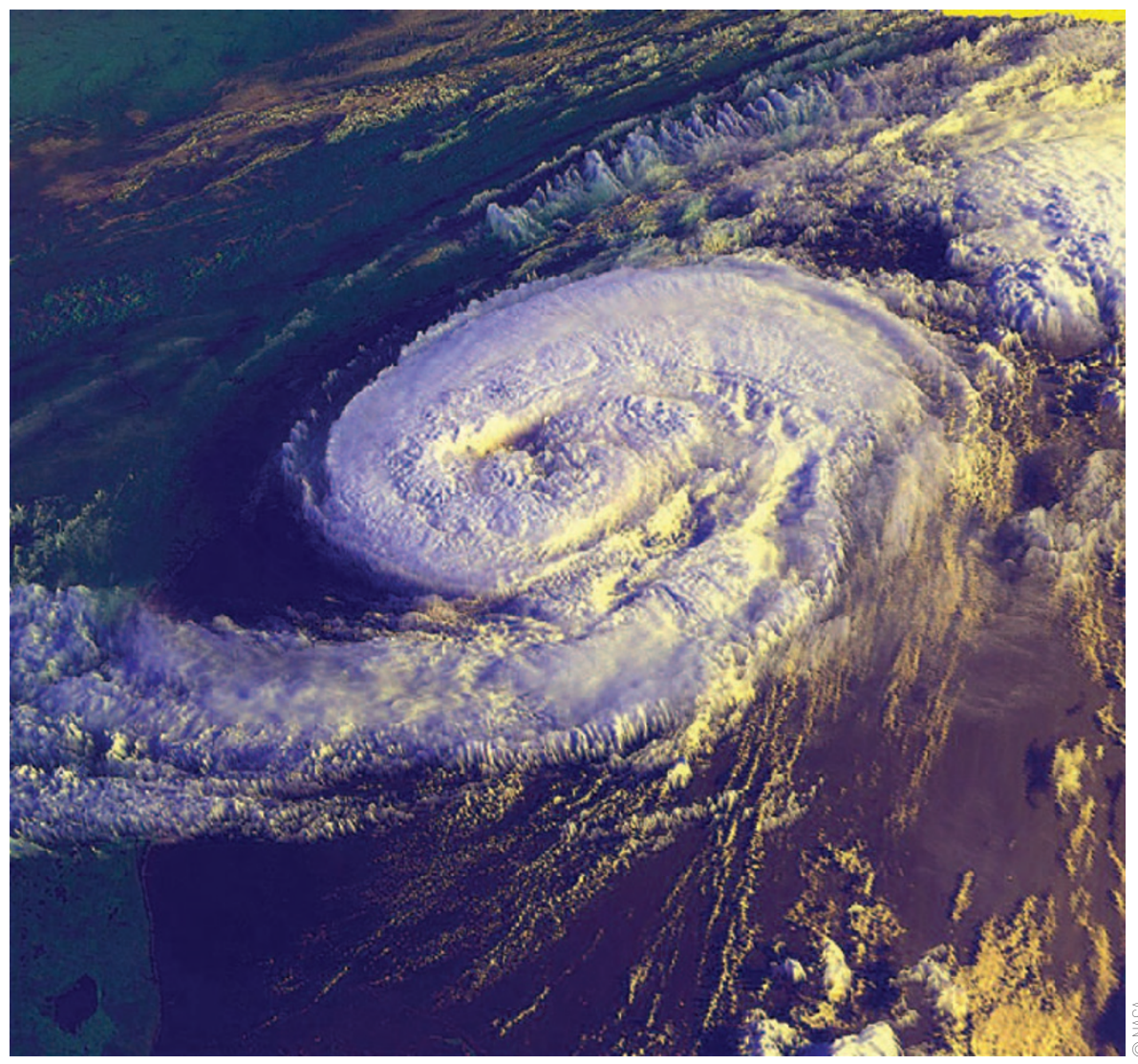

Stormy debates continue between scientists over the evidence linking hurricanes to global warming

He also concludes that the number of reported hurricanes that made landfall from 1900 to 1965 - including 15 years in which $100 \%$ of the recorded tropical cyclones hit land - indicate a strong bias toward undercounting storms over the open oceans. When these biases are corrected, what emerges are very pronounced multi-decadal swings of "busy and quiet" periods, and "the trend pretty much disappears," says Landsea. "Even though we've seen global warming of all the tropical breeding grounds for hurricanes, cyclones and typhoons, the Atlantic is the only area that's had an increase in the number and intensity of these events," Landsea says. "It looks pretty clear that it is part of a natural oscillation and likely doesn't have anything to do with the long-term trend in global warming." Landsea doesn't dispute that global warming has had an impact on hurricane intensity, but rather whether it is possible to detect the subtlety of the change.

\section{Even though we've seen global warming of all the} tropical breeding grounds for hurricanes, cyclones and typhoons, the Atlantic is the only area that's had an increase in the number and intensity of these events. 


\section{BODY OF EVIDENCE}

Other researchers, however, point to examples in which overcounts of the number of tropical cyclones were made in the early part of the century as evidence that Landsea's findings are unlikely to stand up to scrutiny. Kerry Emanuel, professor of meteorology at the Massachusetts Institute of Technology in Cambridge and author of the paper that kicked off the hurricane debate in 2005, says that Landsea's report fails to take into account the evidence for a significant eastward shift in sea-surface temperatures, causing more hurricanes to form farther to the east and fewer to strike the US coastline in recent decades. Greg Holland, a meteorologist at the National Center for Atmospheric Research in Boulder, Colorado, adds that along with an eastward shift, hurricanes are forming closer to the equator. The result, says Holland, is that they are spending more time over warmer water, which creates more favourable breeding grounds for intense hurricanes. "The bad thing that's happening now - and we don't know the end result - is that the proportion of major hurricanes has gone up at the same time that the total number of tropical cyclones has gone up," Holland says. "So we've got a double whammy occurring."

\section{The proportion of major} hurricanes has gone up at the same time that the total number of tropical cyclones has gone up, so we've got a double whammy occurring.

Greg Holland

\section{SHEAR STRENGTH}

To further understand factors that might impact hurricane activity, researchers from NOAA and the University of Miami predicted wind shear of tropical Atlantic hurricanes over the twenty-first century in relation to projected global warming conditions. Vertical wind shear - or how wind direction or speed change due to altitude - has previously been shown to hinder formation of hurricanes and to lessen their intensity once they are underway. They concluded that increased vertical wind shear is likely to strengthen in the Atlantic and could potentially mute the effects of increasing hurricane intensity. "We don't know whether the change would be sufficient to offset entirely the effect of

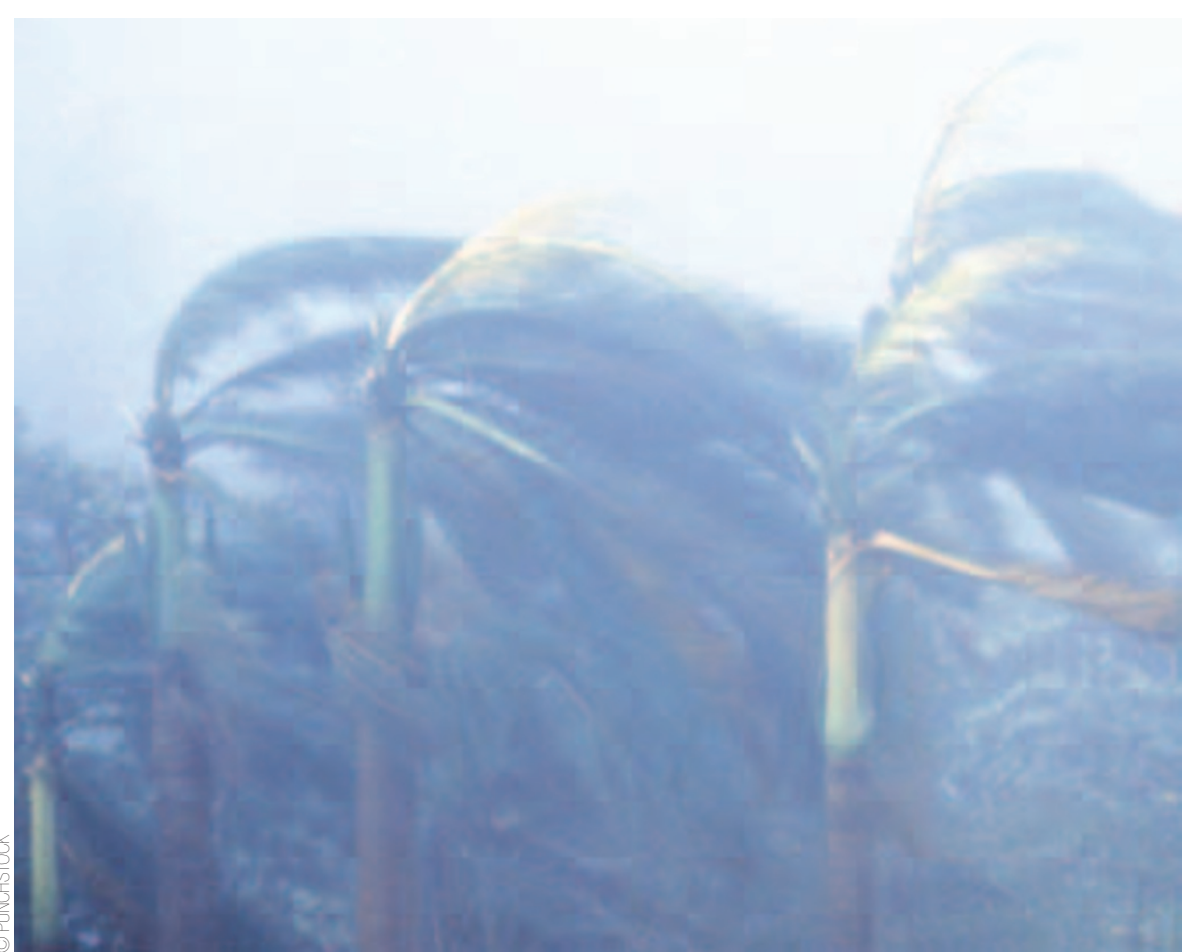

June 1 marked the official start of Atlantic hurricane season

warming oceans," says Gabriel Vecchi, a NOAA climate scientist and lead author of the paper published in the journal Geophysical Research Letters". "But the take-home message is that there's more to hurricanes and global warming than a warming ocean." The study suggests that wind shear is as important as other environmental parameters that affect hurricanes and should be taken into account for projections of hurricane activity. The most recent models used by the Intergovernmental Panel on Climate Change have not had the sensitivity to accurately represent vertical wind shear, says Vecchi.

\section{PAST PATTERNS}

In a recent study published in Nature ${ }^{5}$, scientists from Woods Hole Oceanographic Institution in Massachusetts looked at the role of atmospheric dynamics from El Niño and West-African monsoon patterns over the last 5,000 years in order to understand how such weather events might impact hurricanes in a warming world. The researchers analysed a sediment record from a Caribbean lagoon that contains preserved deposits from hurricane landfalls and found that variations in El Niño and the African jet stream significantly influenced hurricane activity during this period. This confirms a trend that scientists have witnessed over the last several decades in which El Niño episodes tend to weaken
Atlantic hurricanes. An unexpected El Niño event is thought to be the primary reason the 2006 Atlantic hurricane season didn't live up to its dire predictions. But how El Niño patterns will be affected by climate change remains an open question. The researchers also described a 1,000-year period of frequent and intense hurricanes during which ocean temperatures were cooler than today's, indicating that high sea surface temperatures alone are not driving the intensity and frequency of hurricanes.

Holland says the study makes a valuable contribution and drives home the importance of correctly accounting for El Niño and other atmospheric events in climate models. "If we get El Niño wrong, it doesn't matter what else we got right, we're going to get the answer wrong," Holland says. But he and other scientists caution that the study was based on a proxy measurement from a single location, whereas ocean temperatures usually require sampling large swathes of ocean. The conclusions, says Emanuel, "rest upon the part of the analysis that is least robust. It's a sea surface temperature in a very small region around Puerto Rico which could've been influenced by all kinds of things."

Many questions remain outstanding in relation to the links between global warming and hurricane frequency, intensity, duration, size, and even the locations where storms are forming. But a fundamental tenet, according to Kevin Trenberth, a climate researcher at NCAR in Boulder, is that "with global 


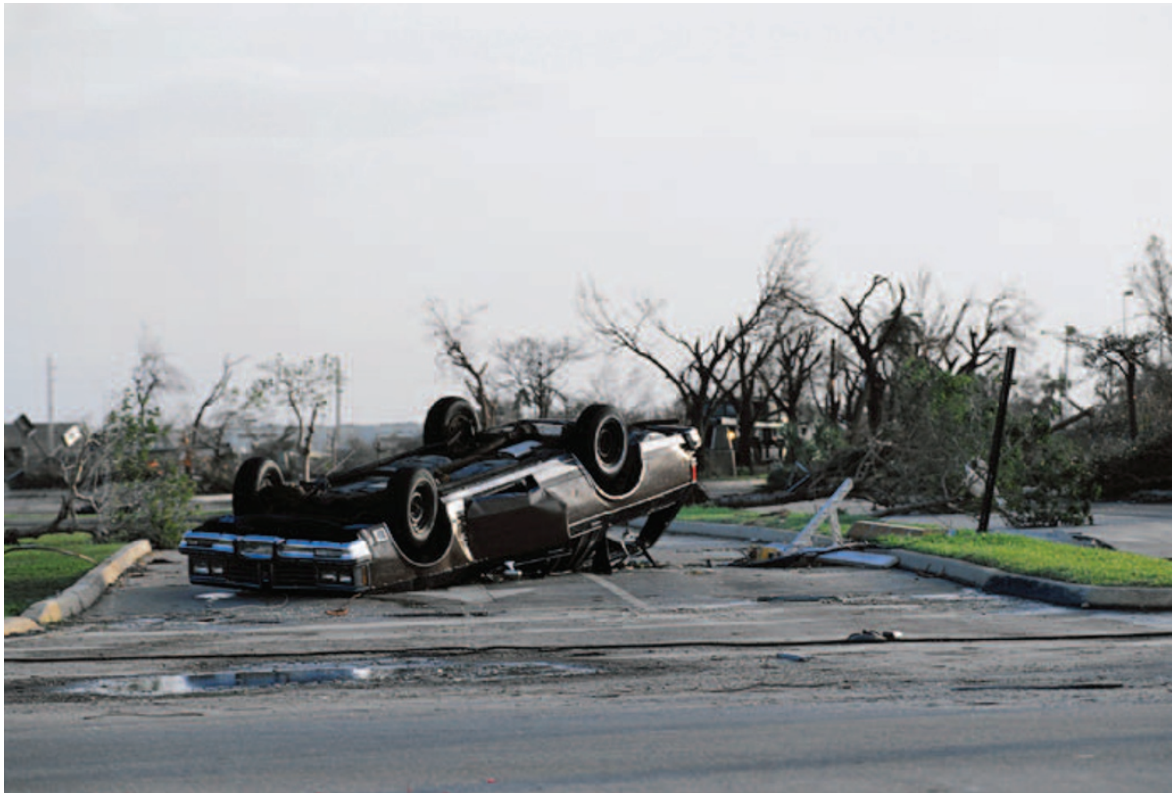

Scientists are predicting the possibility of three to five major hurricanes this season

warming, you have warmer sea-surface temperatures, and extra heat in the ocean that's available to fuel storms." Because of changing atmospheric conditions, Trenberth says, there's a competition for where hurricanes can occur, and "the winner of that competition varies from one year to the next". Even when El Niño and wind shear effects hold sway in three out of four years, "you've got that other year where you can still have lots of activity in the Atlantic", he says.

Regardless of how the debate over climate change and hurricanes shapes up, there is one point the whole meteorology community can agree on: As coastal developments swell, severe damage due to hurricanes smacking the US coast will continue to rise. "It's relatively cheap for someone to go down to the beach and throw up a flimsy structure," says Emanuel. "As long as that continues, even if the climate doesn't change we're going to have one disaster after another."

\section{Amanda Leigh Haag is a freelance} science writer

\section{References}

1. Emanuel, K. Nature 436, 686-688 (2005).

2. Landsea, C. Eos 88, 197-202 (2007).

3. Holland, G. J. \& Webster, P. J. Philos. Trans. R. Soc. Lond. A (in the press).

4. Vecchi, G. A. \& Soden, B. J. Geophys. Res. Lett. 34, L08702 (2007).

5. Donnelly, J. P. \& Woodruff, J. D. Nature 447, 465-468 (2007),

nature REPORTS stem cells

the news behind the science, the science behind the news
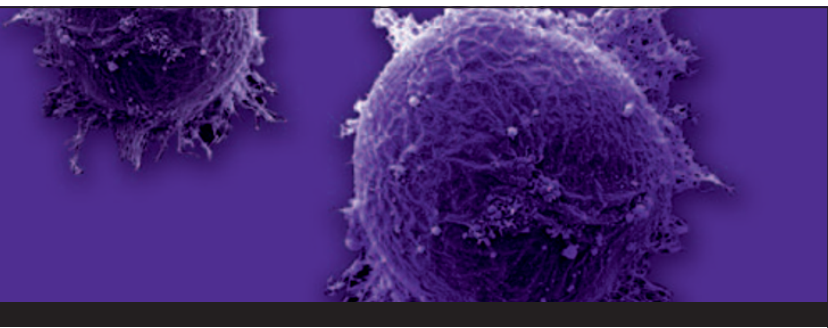

\section{Interested in stem cell news, research, ethics and policy?}

Add this link to your favourites: www.nature.com/reports/stemcells

Nature Reports Stem Cells provides a wealth of material about stem cells and the issues surrounding them, updated weekly.

\section{Features:}

- Specially written material each week

- Contributions from leading figures in the field

- Amalgamated content from Nature Publishing Group's Research and Reviews journals

- Air your opinions in the editors' blog

- Suggest and comment on articles in the Journal Club

- Background information in FAQs and Timelines

\section{Go now to www.nature.com/reports/stemcells and sign up for the monthly newsletter.}

Produced with support from our principal sponsor

ADVANCED C E L L TECHNOLOGY 